\title{
DEPOSITION OF PROTECTIVE COATINGS ON COPPER PLATES OF CCM MOLDS BY THE METHOD OF AUTOVACUUM BRAZING
}

\author{
M.A. POLESHCHUK, M.G. ATROSHENKO, A.V. SHEVTSOVA and A.L. PUZRIN \\ E.O. Paton Electric Welding Institute, NASU \\ 11 Kazimir Malevich Str., 03680, Kiev, Ukraine. E-mail: office@paton.kiev.ua
}

\begin{abstract}
Possibility of applying a protective layer in the form of a thin metal sheet on flat copper panels of CCM molds by autovacuum brazing was verified on models. 08Kh18N10T steel and nickel were used as protective sheets. Peel strength of bimetal brazed joints between the layers was studied, and bending tests were also performed. A sound brazed seam without defects in the form of pores or cracks was produced between the copper plate and 08Kh18N10T steel sheet $2 \mathrm{~mm}$ thick. Peel strength of protective steel layer was equal to $300 \mathrm{MPa}$, on average. Obtained results allow recommending the method of autovacuum brazing for deposition of protective coatings from 08Kh18N10T steel on flat panels of molds. 9 Ref., 6 Figures.
\end{abstract}

Keywords: CCM molds, protective coatings, autovacuum brazing, brazed joints, metallography, mechanics

The major amount of steel produced in the world is poured into water-cooled copper molds, which are replaceable components of continuous casting machines (CCM). During CCM operation, the mold inner surface undergoes abrasive wear, because of friction of solidifying steel crust of the poured billet against the copper water-cooled wall. Particularly intensive and non-uniform wear is observed on the walls of molds designed for producing billets of rectangular or square section in radial-type CCM. Such molds are usually made to consist of separate flat panels with individual cooling. Working surface of some of them can reach one square meter. The service life of such a mold is determined by admissible wear of working surface and can be up to one hundred melts [1].

Service life of CCM molds can be extended in two ways: recovery repair of worn panels or deposition of a protective metal or metal-ceramic coating on their working surface, having higher wear resistance than that of copper.

CCM mold panels are subjected to current repair as required. A layer of copper of thickness greater than that of formed defects, is removed from the working surfaces of cooled copper plates by machining uniformly over the entire plane. During panel operation such repair is repeated several times, until copper plate thickness is reduced to maximum permissible size. Such copper plates can be subjected to reconditioning repair, during which a copper layer is deposited onto their working surface by fusion or friction stir welding process up to restoration of initial thickness $[2,3]$.

In work [4] it is shown that the method of autovacuum brazing (AVB) can be effectively used for reconditioning repair of copper plates of CCM mold panels. This method allows relatively easily applying the restorative copper layer on working surface of copper plates of a large area without distortion or buckling of the latter, that is inherent to other techniques. Brazed seam between the copper layers (base and restorative) is not inferior to copper proper as to strength, and its thermal resistance has practically no influence on the process of heat transfer through the copper plate [4].

In this work, AVB method was used for deposition of protective coatings of metals with higher wear resistance than that of copper, on thick copper cooled plates of molds. The objective of the study was assessment of principal possibility of producing this type of brazed joint and determination of its mechanical properties.

Proceeding from the concepts of the mechanisms of operation of CCM water-cooled molds, let us formulate the main requirements to the properties of protective coatings. They should be dense and wear-resistant; should have good adhesion to copper over the entire wall surface; and minimum thermal resistance to heat flow from molten steel to cooling water.

At present protective coatings from nickel, chromium, steels or ceramics are deposited by electrolytic [1, 5], detonation [5, 6], explosion [7] and other methods. Unfortunately, none of these methods produces a protective coating, the properties of which fully satisfy all the above requirements. So, for instance, with electrolytic or detonation methods, it is impossible to produce a dense coating with good adhesion to copper. This may lead to erosion damage of the coating or its spallation. At cladding of mold copper wall surface with a steel plate by explosion welding, air is trapped in individual regions of the joint. Such air cavities in this location essentially increase thermal resistance to heat flow from the molten metal to cooling water through the wall that is inadmissible in mold operation.

In our opinion, all the above-mentioned requirements to protective coating of the panel wall will be 


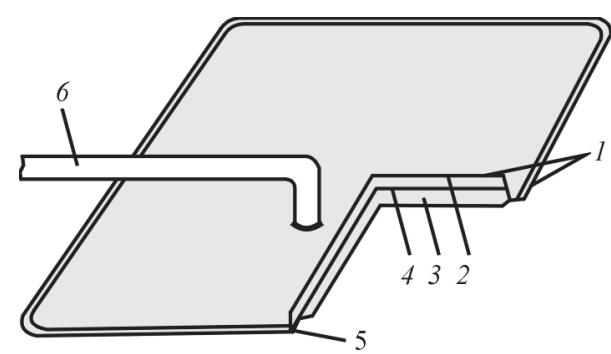

Figure 1. Assembly for brazing: 1 - cassette halves; 2 - protective coating; 3 - base metal, simulating mold panel; 4 - braze alloy; 5 - sealing seam; 6 - vacuum tube

the most completely satisfied by rolled sheet from wear-resistant metal, for instance, from certain grades of steel or nickel, brazed to the copper plate over the entire surface. Such a coating can be deposited on the mold panel during its manufacture or during repair. The complexity of the task is due to the need to have a sound brazed seam over the entire area of the joint of thick copper with wear-resistant sheet.

08Kh18N10T steel and nickel as corrosion-resistant materials with higher wear resistance than that of copper were selected as protective coating for the experiments. $08 \mathrm{Kh} 18 \mathrm{~N} 10 \mathrm{~T}$ steel has thermal expansion factor close to that of copper. This factor is important to achieve the required strength and performance of the brazed joint. In case of application of a less expensive sheet from carbon steels as protective coating, generation of stresses in the brazed seam is inevitable, because of an essential difference in thermal expansion of such steels and copper, that may lead to its failure.

Development of basic technology of AVB of protective coatings was performed experimentally by brazing test packages of $100 \times 100 \mathrm{~mm}$ size by the procedure described in [4]. The packages were assembled from three layers: base metal, simulating mold panel, protective layer and braze alloy between them. Copper of grade M-1 of $7 \mathrm{~mm}$ thickness, was used as the base metal, and protective layers were made from stainless steel $08 \mathrm{Kh} 18 \mathrm{~N} 10 \mathrm{~T} 2 \mathrm{~mm}$ thick, or sheet nickel $4 \mathrm{~mm}$ thick. The braze alloy was foil of beryllium bronze $\mathrm{BrB} 2$ which has shown itself well in brazing multilayer copper packages. Foil of $0.2 \mathrm{~mm}$ thickness, was placed in two layers.

Packages pre-assembled for brazing, were placed into special cassettes, creating a closed volume. The

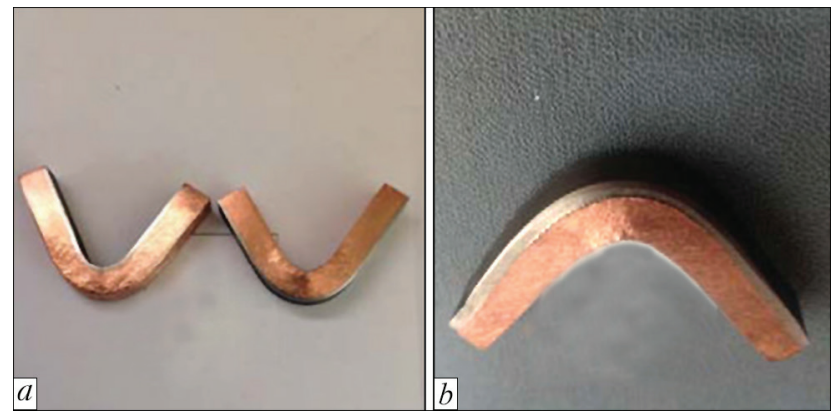

Figure 2. Samples after bending test: $a$ - copper-steel (left protective layer inside, right - outside); $b$ - copper-nickel cassettes consisted of two similar stamped parts. The material for manufacturing the cassettes was $1 \mathrm{~mm}$ thick sheet from $08 \mathrm{Kh} 18 \mathrm{~N} 10 \mathrm{~T}$ steel, which at brazing temperature ensured package compression by atmospheric pressure uniformly over the entire surface. Filled cassettes were welded around the perimeter by argon-arc welding with vacuum-tight weld.

A tube was welded into the cassette for pumping down. General view of the cassette is shown in Figure 1.

Prepared cassettes were placed flat on the table in the heat-treating furnace, vacuum tube was brought outside through a hole in the door, a compound pressure and vacuum gauge, and a backing pump through a gate valve, were connected to it. Before brazing, a rarefaction of $10^{-1}$ was created inside the cassette, and then the gate valve was closed. Heat furnace was heated up to brazing temperature of $1040{ }^{\circ} \mathrm{C}$ with isothermal exposure for $30 \mathrm{~min}$. Cassettes were cooled with the furnace.

After brazing, the cassettes were cut, and samples for investigations were prepared from the removed packages.

First of all, bending test of the samples was conducted to assess the quality of the brazed joint. Samples measuring $80 \times 10 \mathrm{~mm}$ cut out through the entire thickness of the brazed joint, were tested. The samples were bent at $90^{\circ}$ inwards, with the protective layer facing inside and outside (Figure 2).

On copper-steel 08Kh18N10T samples no delamination, cracks or tears were found, either in the first or in the second case in the joint zone. Test results indicate good quality of copper-steel $08 \mathrm{Kh} 18 \mathrm{~N} 10 \mathrm{~T}$ brazed joint, produced with $\mathrm{BrB} 2$ braze alloy.

After testing the copper-nickel sample with protective layer on the outside (Figure 2,b), a delamination occurred in the bending zone. Because of unsatisfactory result of this test, sample bending with protective layer inside was not performed.

Peel testing of brazed bimetal samples was carried out according to the procedure and on samples described in [4]. This procedure is not standard and the normative documents do not provide the values that would define the minimum acceptable peel strength limit for bimetals or layered monometals based on copper. However, this characteristic is important and determines the quality of the brazed joint and performance of the entire item. Thus, the obtained during testing limit values of bimetal peel strength were compared with ultimate tensile strength of monolithic solid copper samples of the same size, made from a copper sheet, similar to base metal prior to brazing. Ultimate tensile strength of monolithic samples was $450 \mathrm{MPa}$, that of copper-steel $08 \mathrm{Kh} 18 \mathrm{~N} 10 \mathrm{~T}$ bimetal was $301.5 \mathrm{MPa}$, that of copper-nickel bimetal was $108 \mathrm{MPa}$. All these data are the averaged results of tests on three samples of each type.

In our opinion, bond strength of copper-steel 08Kh18N10T bimetal obtained with BrB2 braze alloy is high enough to ensure the bimetallic item per- 


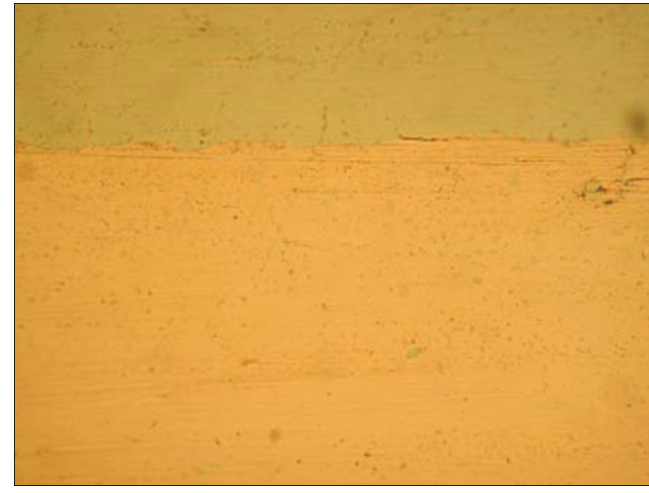

Figure 3. Microstructure $(\times 500)$ of copper-steel $08 \mathrm{Kh} 18 \mathrm{~N} 10 \mathrm{~T}$ brazed joint (unetched state)

formance. To clarify the reasons for the unsatisfactory results of mechanical testing of copper-nickel brazed joint, comparative metallographic analysis of copper-nickel and copper-steel 08Kh18N10T samples was performed. For this purpose, unetched and etched ground samples were studied in NEOFOT 32 microscope at different magnifications. Etching of the samples was carried out in two stages. At the first stage, the sample was etched in an aqueous solution of sulfuric acid, chromic anhydride and sodium chloride to reveal the copper structure. At the second stage, electrochemical etching in chromic anhydride was performed to reveal the structure of stainless steel and nickel.

No clearcut brazed seam is observed in unetched copper-steel 08Kh18N10T microsection $(\times 500)$ (Figure 3). Zone of contact of braze alloy and stainless steel with the size of projections and depressions of 2-15 $\mu \mathrm{m}$, is visible over the entire length of the microsection. The contact zone has no defects such as pores or cracks. All this testifies to the high quality of the brazed joint along the entire length of the studied section.

The width of diffusion zone on steel $08 \mathrm{Kh} 18 \mathrm{~N} 10 \mathrm{~T}$ is equal to $10-50 \mu \mathrm{m}$.

After etching a distinct brazed seam of $60-80 \mu \mathrm{m}$ width is observed (Figure 4). It has finer grain than the copper base metal.

Measurement of microhardness in the brazed joint zone showed that its value is $990-1480 \mathrm{MPa}$ and that of copper base metal is $602-713 \mathrm{MPa}$.

After etching of steel $08 \mathrm{Kh} 18 \mathrm{~N} 10 \mathrm{~T}$ one can see that the size of its grains decreases towards the bound-

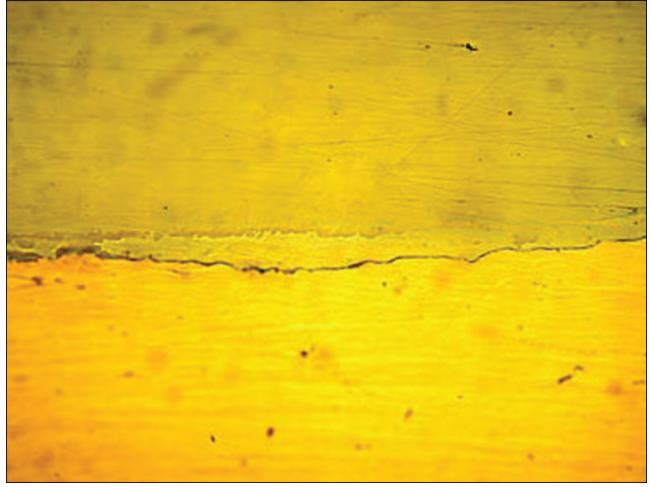

Figure 5. Microstructure $(\times 500)$ of copper-nickel brazed joint (unetched state)

ary with the brazed seam from 40 (in the main part of protective coating) to $5-12 \mu \mathrm{m}$. Microhardness of steel $08 \mathrm{Kh} 18 \mathrm{~N} 10 \mathrm{~T}$ at the boundary is equal to 2480 $2540 \mathrm{MPa}$, and that in the rest of the steel is 2200 $2280 \mathrm{MPa}$. Weld width is $60-80 \mu \mathrm{m}$; diffusion zone from the side of steel $08 \mathrm{Kh} 18 \mathrm{~N} 10 \mathrm{~T}$ is $10-50 \mu \mathrm{m}$, so that the total width of the transition zone of brazed joint is in the range of 70-130 $\mu \mathrm{m}$.

No pores or cracks were observed, when studying bimetal copper-nickel joint on unetched microsection at $\times 500$ magnification. In the area of contact of nickel - BrB2 mutual dissolution of metals (nickel and copper) took place to form a solid solution area 5-15 $\mu \mathrm{m}$ wide (Figure 5).

On the boundary of nickel with the seam, a broken but not dissolved nickel oxide film in the form of interlayers and inclusions, is visible. A brazed seam (BrB2) of the width from 25 to $50 \mu \mathrm{m}$ is observed after copper etching (Figure 6). Seam microhardness is $89 \pm 20 \mathrm{MPa}$.

After electrolytic etching, grains of $100 \times 80 \mu \mathrm{m}$ size with a microhardness of $1390 \pm 200 \mathrm{MPa}$ are observed in the layer of nickel. Nickel region adjacent to the brazed seam, has a recrystallization zone of $25 \mu \mathrm{m}$ width with grain size of 7-15 $\mu \mathrm{m}$. Microhardness of this zone is $2290 \pm 150 \mathrm{MPa}$, which is 1.6 times higher than nickel hardness (Figure 6,b). Such an increase in microhardness is associated with grain refinement in this region.

The brazed seam width is $25-50 \mu \mathrm{m}$, that of recrystallization zone from the nickel side is about $25 \mu \mathrm{m}$. Thus, the total width of the transition zone of this brazed joint is in the range of $25-75 \mu \mathrm{m}$. Lower
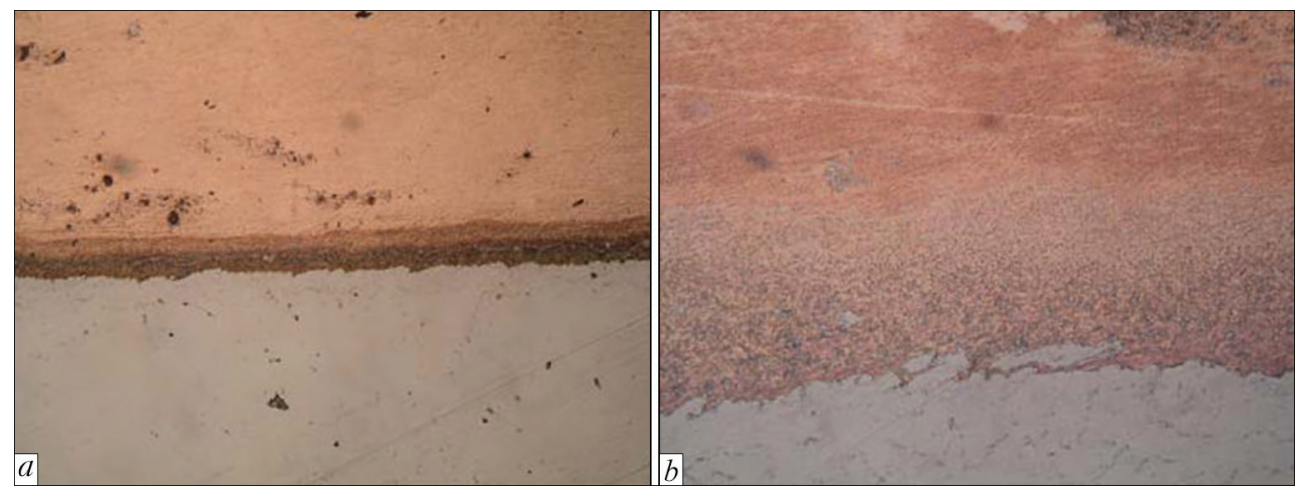

Figure 4. Microstructure of copper-steel $08 \mathrm{Kh} 18 \mathrm{~N} 10 \mathrm{~T}$ brazed joint after etching at different magnifications: $a-\times 100 ; b-\times 1000$ 


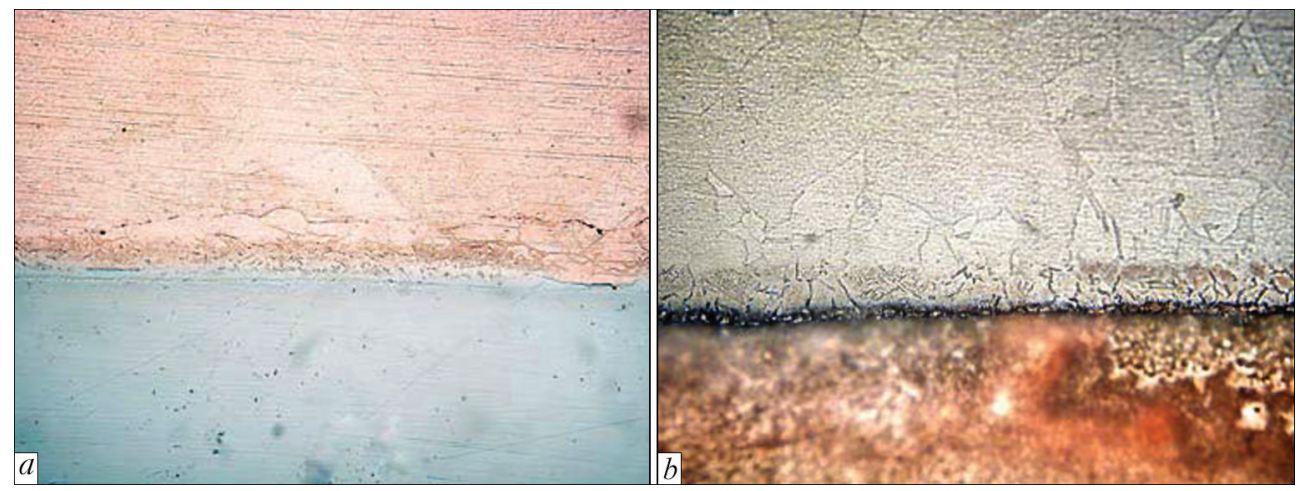

Figure 6. Microstructure of copper-nickel brazed joint after etching: $a-\times 1000 ; b-\times 200$

values of peel strength in nickel-coated samples as compared to samples coated by steel $08 \mathrm{Kh} 18 \mathrm{~N} 10 \mathrm{~T}$, can be explained by presence of undissolved particles of oxide film on nickel surface and in the seam.

Assessing the overall results of the above experimental studies, we can say that a sound joint of the copper plate with the protective layer has so far been obtained by AVB process only for a sheet of steel $08 \mathrm{Kh} 18 \mathrm{~N} 10 \mathrm{~T}$. This joint has no pores, cracks, or tears and the peel strength limit of 08Kh18N10T steel sheet at separation from copper reaches $300 \mathrm{MPa}$ on the average. Such strength value is almost twice higher than the requirements of GOST 10885-85, which specifies the strength characteristics of steel bimetals [8].

During operation CCM molds are among the most heat-loaded industrial units, cooled by water. The specific heat flux transferred from molten steel to water in the mold upper part in the area of liquid metal meniscus can reach $1.8 \mathrm{MW} / \mathrm{m}^{2}$. This value is reduced with greater distance from the metal surface, and at the bottom of the mold it does not exceed $0.46 \mathrm{MW} / \mathrm{m}^{2}$.

Such a change in the specific heat flux is due to appearance of additional thermal resistance in its path below the liquid metal meniscus, which is created by the crust of solidifying future workpiece. Furthermore, a gas gap forms between this crust and the mold wall. This crust thickness increases continuously and at the outlet of the mold it is equal to $15-18 \mathrm{~mm}$ [9].

The protective coating applied to the copper wall in the form of a metal sheet, and the brazed seam also create additional thermal resistance in the heat flux path. However, a protective layer applied to the mold copper wall influences the process of heat transfer only in the upper part of the mold in the region of liquid metal meniscus, where the solidified crust of the future billet is practically absent. Calculations show that protective coating of steel $08 \mathrm{Kh} 18 \mathrm{~N} 10 \mathrm{~T} 1 \mathrm{~mm}$ thick reduces the specific heat flux in the meniscus region by no more than seven percent [9]. Since the area of this zone is much smaller than the area of the walls of the entire mold, it can be assumed that the protective coating applied to the copper wall of the mold by AVB has practically no effect on heat transfer process of the entire unit.

\section{Conclusions}

1. It is experimentally proved that AVB method can be used to produce sound joints of thick copper plates with a sheet of steel $08 \mathrm{Kh} 18 \mathrm{~N} 10 \mathrm{~T}$.

2. Defectfree brazed seams of copper-steel 08Kh18N10T bimetal with high mechanical properties were produced using foil of bronze $\mathrm{BrB} 2$ as braze alloy.

3. AVB method allowed achieving peel strength limit of $08 \mathrm{Kh} 18 \mathrm{~N} 10 \mathrm{~T}$ steel sheet of $300 \mathrm{MPa}$ at separation from the copper plate, which is higher than GOST requirements for corrosion-resistant steel bimetals.

4. Obtained results allow us recommending autovacuum brazing for application of protective coatings on working surfaces of CCM mold panels.

5. The protective coating applied by AVP method on copper walls of the mold has almost no effect on the process of heat transfer throughout the unit.

1. Markushin, A.A., Kuklev, A.V., Ajzin, M.Yu. (2005) Radial slab mold with parallel-plate ducts and nickel coating of walls. Moscow: Metallurgizdat.

2. Abramovich, V.R. (1988) Fusion welding of copper and copper-based alloys. Moscow: Mashinostroenie.

3. Nikityuk, Yu.N., Grigorenko, G.M., Zelenin, V.I. et al. (2013) Technology of restoration repair of slab moulds of MCCB by friction stir surfacing method. Sovremennaya Elektrometallurgiya, 3, 51-55.

4. Grigorenko, G.M., Puzrin, A.L., Atroshenko, M.G. et al. (2015) Autovacuum brazing in repair of copper panels of MCCB moulds. The Paton Welding J., 9, 45-49.

5. Masato, T. (2009) Moulds of MCCB of steel from Mashima kosan. In: Proc. of Int. Sci.-Pract. Seminar on Electrocladding and Thermal Spraying. Ekaterinburg, 20-24.

6. Korobov, Yu.S. (2009) Improvement of service life of metallurgical equipment using thermal spraying. In: Proc. of Int. Sci.-Pract. Seminar on Electrocladding and Thermal Spraying. Ekaterinburg, 56-71.

7. Kudinov, V.M., Koroteev, A.Ya. (1978) Explosion welding in metallurgy. Ed. by E.S. Karakozov. Moscow: Metallurgiya.

8. GOST 10885-85: Sheet hot-rolled two-ply corrosion-resistant steel (OKP 09 950) Introd. 01.07.86: Minchermet SSSR, 1986.

9. Evteev, D.P., Kolybalov, I.N. (1984) Continuous casting of steel. Moscow: Metallurgiya. 